\section{The comparison of individuals over 50 who have played football and the sedentary ones at the same age in terms of quality of life}

\section{0 yaş üstü futbol oynamış bireylerle aynı yaş grubu sedanter bireylerin yaşam kaliteleri bağlamında karşılaştırılmaları ${ }^{1}$}

\author{
Ali İhsan Gönen² \\ İsmail Türkmenoğlu ${ }^{3}$
}

Özet

Bu çalışmada 50 yaş üstü futbol oynamış bireyler ile aynı yaş grubu sedanter bireylerin yaşam kalitesinin karşılaştırılması amaçlanmıştır. Bu araştırmaya Afyonkarahisar ilinde yaşayan 50 yaş üstü futbol oynamış bireyler ile 50 yaş üstü sedanter olarak kabul ettiğimiz düzenli fiziksel aktivite yapmayan toplam 100 birey katılmıştır. Katıllımcilara kişisel bilgi formu, uluslar arası fiziksel aktivite anketi ve araşturma grubunun yaşam kalitesini değerlendirmek için WHO 'nun (1998) geliştirdiği Yaşam Kalitesi Ölçeği kullanılmıştır. Araştırma sonucunda elde edilen veriler SPSS25 programinda analiz edilmiş, araştırmaya katılanların dağılımını belirlemek için frekans ve yüzde analizi, KolmogorvSmirnova analizleri yapılmıs olup verilerin dağılımın normal olduğu belirlendikten sonra, 2'li grupların karşılaştırılmasında bağımsız örneklşem t-testi, 2'den fazla gruplar için tek yönlü Anova Varyans analizi yapılmıştır. Anlamlı farklılığın hangi gruplar arasında olduğunu belirlemek için Scheffe testi yapılmıştır. Sonuç olarak; evil olan katılımcıların bekar olanlara gore, düzenli bir şekilde spor yapanların yapmayanlara göre, haftada 5 gün ve üzerinde spor yapanlarin daha az siklikta

${ }^{1} \mathrm{Bu}$ araştırma yüksek lisans tezinden türetilmiştir.

${ }^{2}$ M.Sc., ihsangonen@hotmail.com (iD Orcid ID: 0000-0001-8906-0912

3Prof. Dr., Afyon Kocatepe Üniversitesi, Veteriner Fakültesi, Anatomi Anabilim Dalı, turkmen@,aku.edu.tr (iD) Orcid ID: 0000-0002-0775-2622 
Gönen, A. İ., \& Türkmenoğlu, İ. (2020). 50 yaş üstü futbol oynamış bireylerle aynı yaş grubu sedanter bireylerin yaşam kaliteleri bağlamında karşılaştırılmaları. Journal of Human Sciences, 17(4), 1312-1322. doi:10.14687/jhs.v17i4.6110

participants in comparison with singles, the ones who do exercises regularly in comparison with those who do not do, the ones who do exercises 5 days or more in a week in comparison with the ones who does less frequently,the ones who are so healthy in general in comparison with the ones who are not, the individuals who do physical activities intensively in comparison with the ones who do not do have a high quality of life.In this sense, individuals over 50 who have played football befor and after 50 and sedentary indiviudals differentiate in terms of quality of life and somehow it is concluded that individuals who do physical activities have a high quality of life in comparison with the other individuals.

Keywords: Football, Sedentary, Sedentary individuals, Quality of life.

Extended English summary is at the end of this document) yapanlara göre, 41 yll ve üzerinde aktif spor yaşamı olanların daha az yıl spor yapanlara göre, genel sağlık durumu çok iyi olanların olmayanlara ve yoğun fiziksel aktivite yapan kişilerin yapmayanlara göre yaşam kalitesinin yüksek olduğu görülmüsstür. Bu da 50 yaş üstü kişilerin 50 yaş öncesinde ve sonrasında futbol oynamıs bireylerle sedanter bireylerin yaşam kalitesi açısından farklılıştığ ve bir şekilde fizksel aktivite yapmış kişilerin diğer bireylere göre yaşam kalitesinin yüksek olduğu sonucuna varılmıştır.

Anahtar Kelimeler: Futbol, Sedanter, Sedanter Birey, Yaşam Kalitesi.

\section{Giriş}

Spor, yapanlar için kazanmaya dayalı teknik ve fiziki bir uğraş iken, izleyenler için yarışmaya dayalı olan estetik süreçtir. Toplum açısından ise, zaman zaman özelliklerini ve çelişkilerini aktaran bir yayın, zaman zaman ise toplumu yönlendiren bir amaçtır. Genel anlamda toplum açısından önemli bir kurumdur (Özdoğan, 2008). Bugünün modern dünyasında vazgeçilmez bir ihtiyaç olan spor, en gelişmiş ülkeler tarafından da yatırım yapılan en önemli alanlardan biridir. Spor; insanların psikolojik, sosyo-ekonomik ve psikomotor becerilerini karşılayan bir gerekliliktir (Akcan, 2013).

Günümüzde spor, toplumlar arasında kültürel, ekonomik ve sosyal anlamda gelişimini sürdürerek iletişimin kurulmasında önemli bir etken olmuştur. Bilhassa futbol, tüm toplumlarda en fazla seyirci katıllımının ve potansiyelinin olduğu spor faaliyeti haline gelmiştir (İmamoğlu, Koçak ve Sunay, 1996). Müsabaka alanının geniş olması, oyuncu sayısının fazlalı̆̆1 ve kazanmaya, rekabete yönelik oluşundan dolayı diğer spor dallarından kolayca ayrılmaktadır (Köklüe ve ark., 2009).

Hareketsiz yaşam ve az hareket etme durumunda hayatını devam ettiren sedanter bireyler, düzenli egzersiz yapan sporculara göre daha olumsuz beden bütünlüğünde ve daha mutsuz oldukları bilinmektedir. Düzenli bir şekilde spor yapan kişiler ile sedanter yaşam tarzına sahip olanlar ve bunların yaşam kaliyesi üzerine önceki yıllarda pek çok araştırma yapılmıştır (Gümüş ve Işık, 2018; Y1lmaz ve ark., 2019).

Gün içerisinde kişilerin yapmış olduğu hemen hemen her işte teknolojik aletlerin etkisinin artması, ulaşımda sağlanan kolaylıklar, bilgisayar, akıllı ev aletlerin kullanımının yaygılaşması fiziksel aktiviteleri kısıtlayarak enerji harcamasını azalmıştır. Kişinin yaşı ilerledikçe de fiziksel aktivitenin düşüş göstermesiyle de enerji ihtiyacı daha az olmaktadır (Çolakoğlu, 2003).

Toplumda sağlıkl bireylerin olması için fiziksel aktivitenin yararlarının bilinmesi ve kişiye uygun fiziksel aktivitelerin yapılması gerekmektedir. Yaşamın uzun ve kaliteli olmasında fiziksel aktivitelerin etkisi oldukça yüksektir. Yalnız çocukluk döneminde yapılmış olan fiziksel aktiviteler yeterli değildir. Bunun yanı sıra yetişkinlik ve yaşlılık dönemlerinde de fiziksel aktivitenin yapılması 
Gönen, A. İ., \& Türkmenoğlu, İ. (2020). 50 yaş üstü futbol oynamış bireylerle aynı yaş grubu sedanter bireylerin yaşam kaliteleri bağlamında karşılaştırılmaları. Journal of Human Sciences, 17(4), 1312-1322. doi:10.14687/jhs.v17i4.6110

yaşam kalitesini etkileyen öenmli bir unsurdur (Yüksel, 2001; akt: Fişne, 2009; Gümüş ve Erbaş, 2020; Koçak ve ark. 2017; Işı1k ve ark., 2014).

Vural, Eler ve Atalay Güzel (2010), yapmış oldukları çalışma sonucunda, Ankara ilinde masa başında çalışmakta olan kişilerin fiziksel aktivite seviyeleri ve yaşam kaliteleri arasındaki ilişki açıklanmaya çalısılmışır. Ancak bu kişilerin fiziksel aktivite yapma seviyelerinin düşük olduğu ve yaşam kalitesi skorları ile fiziksel aktivite seviyeleri arasında anlamlı bir ilişki bulunamamışır.

Brown ve arkadaşları (2003), 175.850 yetişkinin katılmıs olduğu fiziksel aktiviteyle yaşam kalitesi ilişkisinin incelendiği çalışmalarında, 2001 Davranışsal Risk Faktörü İzleme anketini kullanmışlardır. Olasılık oranlarını belirlemek için, etnik durum, yaş, cinsiyet, eğitim durumu, vücut kitle endeksleri ve sigara içme durumları gibi değişenler üzerinde $\% 95$ güven aralığı ile çok değişkenli regresyon analizi uygulanmıştır. Analizler sonucunda elde edilen bulgulara göre; etnik durum, yaş ve cinsiyet grupları için, 15 gün fiziksel ve zihinsel oarak aktivite yapanlar, fiziksel aktivite yapma seviyesinde olanlar arasında anlamlı bir farklılık bulunmuştur.

Bu çalışmada; 50 yaş üstü futbol oynamış bireyler ileaynı yaş grubu üstü sedanter bireylerin yaşam kalitesi açısından incelenmesi amaçlanmıştur.

\section{Materyal ve Yöntem}

Araştırmanın Modeli: Bu çalışma araştırmacıların anket yoluyla katılımcıların belli bir konuya yönelik görüşlerini topladıkları ve bu görüşleri gruplar arasında karşılaştırmalarını sağlayan niceliksel araştırma modellerinden, nedensel karşılaştırma modelindedir (Fraenkel, Wallen, ve Hyunn, 2012).

Araştırma Grubu: Bu araştırmanın evrenini Afyon ilinde yaşayan 50 yaş üstü futbol oynayan bireyler, örneklemini ise anketleri doldurmayı kabul eden gönüllü 100 (50 düzenli fiziksel aktivite yapan, 50 düzenli fiziksel aktivite yapmayan) bireylerden oluşturmaktadır. Veri toplama araçlarından anket formu Mart 2019 tarihinde araştırmacı tarafindan sahaya sunulmuştur. Anketi cevaplayan bireylerin sayısına bakıldı̆̆ında ölçekteki madde sayısının yaklaşık 4 katına ulaşılmıştır.

Veri Toplama Aracı: Araştırmada elde edilen verilerin toplanması için üç bölümden oluşan anket formu kullanılmıştır. Araştırmada kullanılan anket formunun birinci bölümünde katılımciların demografik özelliklerinin belirlenmesi için 6 adet sorunun yanı sıra, kaç yıldır aktif olarak sporla uğraştıkları, düzenli olarak fiziksel aktivite yapıp yapmadıkları ve genel olarak sağlık durumlarını nasıl değerlendirdiklerine yönelik sorulara yer verilmiştir. Anketin ikinci bölümünde katılımcıların fiziksel aktivite düzeylerini belirlemek için "Uluslararası Fiziksel Aktivite Değerlendirme Anketi Kısa Formu" kullanılmış olup anketin üçüncü bölümünde katılımcıların yaşam kalitesi düzeylerini belirlemek için 23 soruluk, beşli likert tipli ölçek sunulmuştur. Veri toplama bölümlerine ait detaylı bilgiler aşağıda sunulmuştur.

Uluslararası Fiziksel Aktivite Değerlendirme Anketi Kısa Formu: Uluslararası Fiziksel Aktivite Değerlendirme Anketi (IPAQ) katılımcıların fiziksel aktivite düzeylerini belirlemek amacıyla geliştirilmiştir (Craig, Marshall, Sjostrom, Bauman, Booth, 2003). IPAQ, uluslararası arenada günlük olarak yapılan fiziksel aktiviteyi bireysel raporlara dayanarak fiziksel aktivite düzeyi hakkında geçerli ve karşılaştırılabilir bilgi elde etmek amacıyla geliştirilmiştir. Türkiye’ de Öztürk tarafindan 2005 yllinda üniversitelerde eğitim-öğretim gören öğrencilerde ayrıca Hacettepe Üniversitesi Spor Bilimleri ve Teknolojisi Yüksekokulu Tarafindan 2007 yllında IPAQ anketinin geçerlik ve güvenirlik çalışması yapılmıştır (Karaca ve Turnagöl, 2007).

IPAQ Anketinin Puanlanmast ve Skorlamasi: Kısa form (7 soru); yürüme, orta şiddetli ve şiddetli aktivitelerde harcanan zaman ve otururken harcanan zaman hakkında bilgi sağlamaktadır. Kısa formun toplam skorunun hesaplanması yürüme, orta şiddetli aktivite ve şiddetli aktivitenin süre (dakikalar) ve frekans (günler) toplamını içermektedir. Aktiviteler için gerekli olan enerji MET-dakika skoru ile hesaplanır. Bu aktiviteler için standart MET değerleri oluşturulmuştur. Bunlar;

Yürüme $=3.3$ MET, Orta Şiddetli Fiziksel Aktivite $=4.0$ MET, Şiddetli Fiziksel Aktivite = 8.0 MET, Oturma $=1.5$ MET. 
Gönen, A. İ., \& Türkmenoğlu, İ. (2020). 50 yaş üstü futbol oynamış bireylerle aynı yaş grubu sedanter bireylerin yaşam kaliteleri bağlamında karşılaştırılmaları. Journal of Human Sciences, 17(4), 1312-1322. doi:10.14687/jhs.v17i4.6110

Bu değerler kullanılarak günlük ve haftalık fiziksel aktivite seviyesi hesaplanır. Örneğin; 3 gün 30 dakika yürüyen bir kişinin yürüme MET-dk/hafta skoru: 3.3*3*30 = 297 MET-dk/hafta olarak hesaplanmaktadır.

Bu sürekli skorlamanın yanı sıra elde edilen sayısal verilere göre sınıflandırma yapılmaktadır. Buna göre 3 aktivite seviyesi vardır:

1. İnaktif (Kategori 1): En alt fiziksel aktivite seviyesidir. Kategori 2 ve 3 içine dâhil edilemeyen durumlar inaktif olarak düşünülür.

2. Minimal Aktif (Kategori 2): Aşağıdaki kriterlerden herhangi birine girenler minimal aktiftir. a. 3 veya daha fazla gün en az 20 dakika şiddetli aktivite yapmak b. 5 veya daha fazla gün orta şiddetli aktivite veya yürümenin günde en az 30 dakika yapılması c. Minimum 600 MET-dk/haftayı sağlayan 5 veya daha fazla gün yürüme ve orta şiddetli aktivitenin birleşimi

3. Çok Aktif (Kategori 3): Bu ölçüm yaklaşık olarak en az günde bir saat veya daha fazla olan orta şiddetli bir aktiviteye eşittir. Bu kategori, sağlıkla ilgili yararların sağlanmasında gereken düzeydir. A. Minimum 1500 MET-dk/haftayı sağlayan en az 3 gün şiddetli aktivite veya b. Minimum 3000 MET-dk/haftayı sağlayan 7 veya daha fazla gün yürüme

Yaşam Kalitesi Ölçeği: Araştırma grubunun yaşam kalitesini değerlendirmek için WHO'nun (1998) geliştirdiği 23 madde ve 5 alt boyuttan oluşan Yaşam Kalitesi Ölçeği "World HealthOrganizationQuality of Life (WHOQOL-BREF)" kullanılmıştır. Ölçeğin alt boyutları; Fiziksel Kalite (3 madde), Psikolojik Kalite (5 madde), Sosyal Kalite (3 madde), Çevresel Kalite (6 madde), Bağımsızlık Kalitesi (6 madde) şekildedir. Araştırmada kullanılan ölçeklerin her birinde aralıklı ölçüm düzeyi olarak kabul edilen 5'li Likert Ölçeği kullanılmıştır. Ölçeğin Türkçe geçerlik güvenirlik çalışması Sevil (2015) trafindan yapılmıştır. Ölçeğin Tükçe formunda WHO'nun geliştirdiği Yaşam Kalitesi Ölçeğinden farklı olarak faktör yük değerleri ve ortak varyans değerleri yüksek olan 23 maddenin oluşturduğu beş faktörlü bir yapı elde edilmiştir. Bu araştırmada yaşam kalitesi ölçeğine ait güvenirlik düzeyinin 0,954 ile yüksek seviyede olduğu belirlenmiştir.

Verilerin Analizi: Araşturma sonucunda elde edilen veriler SPSS 25 programında analiz edilmiştir. Araştırmaya katılanların dağılımlarını belirlemek için frekans ve yüzde analizi, katılımcılardan elde edilen verilerin dağılımlarının incelenmesi için normal dağılım analizlerinden kolmogorov-smirnov analizleri yapılmış olup verilerin dağılımın normallikten geldiği belirlendikten sonra, 2’li grupların karşılaştırılmasında bağımsız örneklem t-tesi, ikiden fazla gruplar için tek yönlü varyans analizi yapılmıştır. Varyans analizinde anlamlı farklıllğın hangi gruplardan meydana geldiğini belirlemek için post-hoc analizlerinden scheffe analizi yapılmıştır. Kategorik değişken arasındaki ilişkilerin belirlenmesinde ki-kare analizi yapılmıştır. Araştırmada kullanılan yaşam kalitesi ölçeğine ait güvenirlik düzeylerinin belirlenmesinde Cronbach's Alpha analizi yapılmıştır. Anlamlılık seviyesi $\mathrm{p}<$ 0,05 olarak belirlenmiştir.

\section{Bulgular}

Tablo 1. Katılımcıların Yaşam Kalitesi Düzeylerinin Medeni Durumlarına Göre Farklılaşma Durumuna Ait Bağımsız Örneklem T-testi Sonuçları

\begin{tabular}{|c|c|c|c|c|c|c|}
\hline Ölçek/Boyutlar & Medeni Durum & $\mathrm{n}$ & $\overline{\bar{X}}$ & SS & $\bar{t}$ & $\bar{p}$ \\
\hline \multirow{2}{*}{ Fiziksel Kalite } & Evli & 57 & 3,34 & 1,14 & \multirow{2}{*}{3,696} & \multirow{2}{*}{$0,000^{* *}$} \\
\hline & Bekâr & 43 & 2,51 & 1,07 & & \\
\hline \multirow{2}{*}{ Psikolojik Kalite } & Evli & 57 & 3,09 & 0,68 & \multirow{2}{*}{2,302} & \multirow{2}{*}{$0,023^{*}$} \\
\hline & Bekâr & 43 & 2,77 & 0,68 & & \\
\hline \multirow{2}{*}{ Bağımsızlık Kalitesi } & Evli & 57 & 3,20 & 0,71 & \multirow{2}{*}{3,805} & \multirow{2}{*}{$0,000^{* *}$} \\
\hline & Bekâr & 43 & 2,65 & 0,73 & & \\
\hline \multirow{2}{*}{ Sosyal Kalite } & Evli & 57 & 3,42 & 1,18 & \multirow{2}{*}{3,154} & \multirow{2}{*}{$0,002^{* *}$} \\
\hline & Bekâr & 43 & 2,71 & 1,02 & & \\
\hline
\end{tabular}


Gönen, A. İ., \& Türkmenoğlu, İ. (2020). 50 yaș üstü futbol oynamış bireylerle aynı yaș grubu sedanter bireylerin yașam kaliteleri bağlamında karșılaştırılmaları. Journal of Human Sciences, 17(4), 1312-1322. doi:10.14687/jhs.v17i4.6110

\begin{tabular}{lllllll}
\hline \multirow{2}{*}{ Çevresel Kalite } & Evli & 57 & 3,43 & 1,09 & 3,781 & $0,000^{* *}$ \\
& Bekâr & 43 & 2,61 & 1,05 & & $0,000^{*}$ \\
\hline \multirow{2}{*}{ Yaşam Kalitesi Düzeyi } & Evli & 57 & 3,28 & 0,87 & 3,656 & 0,82 \\
\hline
\end{tabular}

$* * \mathrm{p}<0.01 ;{ }^{*} \mathrm{p}<0.05$

Katılımcıların yaşam kalitesi düzeylerinin medeni durumlarına göre anlamlı bir farklılık gösterip göstermediğini belirlemek amacıyla yapılan bağımsız örneklem t-testi sonucunda; katılımcıların genel yaşam kalitesi düzeylerinin medeni durumlarına göre farkının istatistiksel olarak anlamlı olduğu belirlendiğinden $(\mathrm{t}=3,656 ; \mathrm{p}<0.01) \mathrm{H}_{1}$ hipotezi kabul edilmiştir. Evli $\left(\mathrm{x}^{-}=3,28\right)$ olanların yaşam kalitesi düzeylerinin bekâr $\left(\mathrm{x}^{-}=2,66\right)$ olanlara göre daha yüksek olduğu belirlenmiştir.

Tablo 2. Katılımcıların Yaşam Kalitesi Düzeylerinin Düzenli Spor Yapma Durumlarına Göre Farklılaşma Durumuna Ait Bağımsız Örneklem T-testi Sonuçları

\begin{tabular}{|c|c|c|c|c|c|c|}
\hline Ölçek/Boyutlar & Düzenli Spor Yapma & $\mathrm{n}$ & $\bar{X}$ & SS & $\mathrm{t}$ & $\mathrm{p}$ \\
\hline \multirow{2}{*}{ Fiziksel Kalite } & Evet & 50 & 4,02 & 0,61 & \multirow{2}{*}{18,823} & \multirow{2}{*}{$0,000^{* *}$} \\
\hline & Hayır & 50 & 1,95 & 0,48 & & \\
\hline \multirow{2}{*}{ Psikolojik Kalite } & Evet & 50 & 3,51 & 0,47 & \multirow{2}{*}{13,470} & \multirow{2}{*}{$0,000 * *$} \\
\hline & Hayır & 50 & 2,40 & 0,35 & & \\
\hline \multirow{2}{*}{ Bağımsızlık Kalitesi } & Evet & 50 & 3,61 & 0,43 & \multirow{2}{*}{16,094} & \multirow{2}{*}{$0,000^{* *}$} \\
\hline & Hayır & 50 & 2,31 & 0,37 & & \\
\hline \multirow{2}{*}{ Sosyal Kalite } & Evet & 50 & 4,13 & 0,59 & \multirow{2}{*}{18,718} & \multirow{2}{*}{$0,000^{* *}$} \\
\hline & Hayır & 50 & 2,09 & 0,50 & & \\
\hline \multirow{2}{*}{ Çevresel Kalite } & Evet & 50 & 4,08 & 0,63 & \multirow{2}{*}{18,201} & \multirow{2}{*}{$0,000^{* *}$} \\
\hline & Hayır & 50 & 2,08 & 0,45 & & \\
\hline \multirow{2}{*}{ Yaşam Kalitesi Düzeyi } & Evet & 50 & 3,83 & 0,49 & \multirow{2}{*}{22,403} & \multirow{2}{*}{$0,000^{* *}$} \\
\hline & Hayır & 50 & 2,19 & 0,16 & & \\
\hline
\end{tabular}

$* * \mathrm{p}<0.01$

Tablo 2 incelendiğinde Katılımcıların yaşam kalitesi düzeylerinin düzenli spor yapma durumlarına göre anlamlı bir farklılık gösterip göstermediğini belirlemek amacıyla yapılan bağımsız örneklem t-testi sonucunda; katılımcıların genel yaşam kalitesi düzeylerinin düzenli spor yapmaya göre farkının istatistiksel olarak anlamlı olduğu belirlendiğinden $(\mathrm{t}=22,403 ; \mathrm{p}<0.01) \mathrm{H}_{2}$ hipotezi kabul edilmiştir. Düzenli spor yapanların $(\bar{X}=3,83)$ yaşam kalitesi düzeylerinin düzenli spor yapmayanlara $\left(\mathrm{x}^{-}=2,19\right)$ göre daha yüksek olduğu tespit edilmiştir.

Tablo 3. Katılımcıların Yașam Kalitesi Düzeylerinin BKI Gruplarına Göre Farklılaşma Durumuna Ait Anova Analizi Sonuçları

\begin{tabular}{lllcccc}
\hline Ölçek/Boyutlar & BKI & n & $\overline{\boldsymbol{X}}$ & SS & F & p \\
\hline \multirow{3}{*}{ Fiziksel Kalite } & Zayıf & 20 & 3,02 & 1,35 & & \multirow{2}{*}{0,282} \\
& Normal Kilolu & 48 & 3,15 & 1,07 & 1,281 & \\
\hline \multirow{3}{*}{ Psikolojik Kalite } & Fazla Kilolu & 32 & 2,72 & 1,21 & & \\
& Zaylf & 20 & 3,05 & 0,73 & & \\
& Normal Kilolu & 48 & 2,98 & 0,63 & 0,634 & 0,533 \\
& Fazla Kilolu & 32 & 2,84 & 0,76 & & \\
\multirow{3}{*}{ Bağı̆msızlık Kalitesi } & Zayıf & 20 & 3,08 & 0,88 & & \\
& Normal Kilolu & 48 & 3,03 & 0,68 & \multirow{2}{*}{1,337} & 0,267 \\
& & 32 & 2,78 & 0,80 & & \\
\hline
\end{tabular}


Gönen, A. İ., \& Türkmenoğlu, İ. (2020). 50 yaş üstü futbol oynamış bireylerle aynı yaş grubu sedanter bireylerin yaşam kaliteleri bağlamında karşılaştırılmaları. Journal of Human Sciences, 17(4), 1312-1322. doi:10.14687/jhs.v17i4.6110

\begin{tabular}{|c|c|c|c|c|c|c|}
\hline \multirow{3}{*}{ Sosyal Kalite } & Zayif & 20 & 3,32 & 1,36 & \multirow{3}{*}{1,943} & \multirow{3}{*}{0,149} \\
\hline & Normal Kilolu & 48 & 3,24 & 1,03 & & \\
\hline & Fazla Kilolu & 32 & 2,78 & 1,19 & & \\
\hline \multirow{3}{*}{ Çevresel Kalite } & Zayif & 20 & 3,15 & 1,32 & \multirow{3}{*}{2,691} & \multirow{3}{*}{0,073} \\
\hline & Normal Kilolu & 48 & 3,30 & 0,97 & & \\
\hline & Fazla Kilolu & 32 & 2,71 & 1,21 & & \\
\hline \multirow{3}{*}{ Yaşam Kalitesi Düzeyi } & Zayıf & 20 & 3,11 & 1,04 & \multirow{3}{*}{1,772} & \multirow{3}{*}{0,175} \\
\hline & Normal Kilolu & 48 & 3,13 & 0,79 & & \\
\hline & Fazla Kilolu & 32 & 2,77 & 0,94 & & \\
\hline
\end{tabular}

Tablo 3 incelendiğinde, katıllımcıların yaşam kalitesi düzeylerinin BKI gruplarına göre anlamlı bir farklılık gösterip göstermediğini belirlemek amacıyla yapılan anova analizi sonucunda; katılımcıların genel yaşam kalitesi düzeyleri ve alt boyutlanının BKI gruplanna göre farkının istatistiksel olarak anlamlı olmadığı belirlenmiştir.

Tablo 4 incelendiğinde katılımcıların yaşam kalitesi düzeylerinin IPAQ gruplarına göre anlamlı bir farklılık gösterip göstermediğini belirlemek amacıyla yapılan anova analizi sonucunda; katılımcıların genel yaşam kalitesi düzeyleri IPAQ gruplarına göre farkının istatistiksel olarak anlamlı olduğu belirlendiğinden $(\mathrm{F}=1892,188 ; \mathrm{p}<0.01)$ H10 hipotezi kabul edilmiştir. IPAQ grubu çok aktif $(\bar{X}=4,25)$ olanların yaşam kalitesi düzeyleri IPAQ grubu inaktif $(\bar{X}=2,19)$ veminimal olanlara $(\bar{X}=$ $3,30)$ göre daha yüksek olduğu tespit edilmiştir.

Tablo 5 Kattlımciların IPAQ düzeyleri ile düzenli olarak fiziksel aktivite yapma durumları arasındaki ilişkiyi belirlemek için ki-kare analizi yapılmıştır. Yapılan ki-kare analizi sonucuna göre IPAQ grupları ile düzenli olarak fiziksel aktivite yapma arasında anlamlı bir ilişki olduğu $\left(X^{2}=100,0\right.$; $\mathrm{p}<0.01$ ) belirlendiğinden H11 kabul edilmiştir. Fiziksel aktivite yapanların \%44’ünün minimal IPAQ grubunda, \%56'sının ise çok aktif IPAQ grubunda oldukları düzenli olarak fiziksel aktivite yapmayanların ise tamamının inaktif IPAQ grubunda oldukları belirlenmiştir.

Tablo 4. Katılımcıların Yaşam Kalitesi Düzeylerinin IPAQ Grubuna Göre Farklılaşma Durumuna Ait Anova Analizi Sonuçları.

\begin{tabular}{|c|c|c|c|c|c|c|c|}
\hline Ölçek/Boyutlar & IPAQ & $\mathrm{n}$ & $\overline{\bar{X}}$ & SS & $F$ & $\mathrm{p}$ & Scheffe \\
\hline \multirow{3}{*}{ 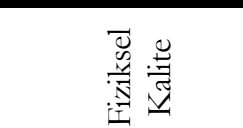 } & İnaktif & 50 & 1,95 & 0,48 & \multirow{3}{*}{373,086} & \multirow{3}{*}{$0,000 * *$} & \multirow{3}{*}{$\begin{array}{l}1-3 \\
2-3\end{array}$} \\
\hline & Minimal & 22 & 3,42 & 0,29 & & & \\
\hline & Çok Aktif & 28 & 4,49 & 0,31 & & & \\
\hline \multirow{3}{*}{ 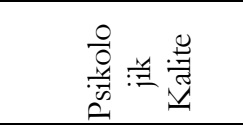 } & İnaktif & 50 & 2,40 & 0,35 & \multirow{3}{*}{219,434} & \multirow{3}{*}{$0,000 * *$} & \multirow{3}{*}{$\begin{array}{l}1-3 \\
2-3\end{array}$} \\
\hline & Minimal & 22 & 3,05 & 0,26 & & & \\
\hline & Çok Aktif & 28 & 3,86 & 0,21 & & & \\
\hline \multirow{3}{*}{ 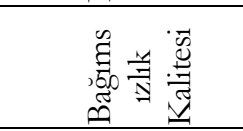 } & İnaktif & 50 & 2,31 & 0,37 & \multirow{3}{*}{319,069} & \multirow{3}{*}{$0,000 * *$} & $1-3$ \\
\hline & Minimal & 22 & 3,15 & 0,17 & & & \multirow[t]{2}{*}{$2-3$} \\
\hline & Çok Aktif & 28 & 3,97 & 0,11 & & & \\
\hline \multirow{3}{*}{ 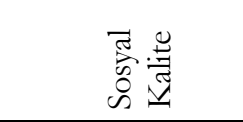 } & İnaktif & 50 & 2,09 & 0,50 & \multirow{3}{*}{365,12} & \multirow{3}{*}{$0,000 * *$} & \multirow{3}{*}{$\begin{array}{l}1-3 \\
2-3\end{array}$} \\
\hline & Minimal & 22 & 3,55 & 0,26 & & & \\
\hline & Çok Aktif & 28 & 4,60 & 0,26 & & & \\
\hline \multirow{3}{*}{ 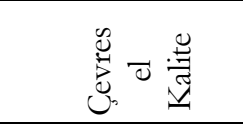 } & İnaktif & 50 & 2,08 & 0,45 & \multirow{3}{*}{371,898} & \multirow{3}{*}{$0,000 * *$} & \multirow{3}{*}{$\begin{array}{l}1-3 \\
2-3\end{array}$} \\
\hline & Minimal & 22 & 3,47 & 0,28 & & & \\
\hline & Çok Aktif & 28 & 4,56 & 0,35 & & & \\
\hline \multirow{3}{*}{ 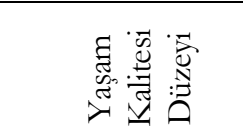 } & İnaktif & 50 & 2,19 & 0,16 & \multirow{3}{*}{1892,188} & \multirow{3}{*}{$0,000^{* *}$} & \multirow{3}{*}{$\begin{array}{l}1-3 \\
2-3\end{array}$} \\
\hline & Minimal & 22 & 3,30 & 0,12 & & & \\
\hline & Çok Aktif & 28 & 4,25 & 0,12 & & & \\
\hline
\end{tabular}


Gönen, A. İ., \& Türkmenoğlu, İ. (2020). 50 yaş üstü futbol oynamış bireylerle aynı yaş grubu sedanter bireylerin yaşam kaliteleri bağlamında karşılaştırılmaları. Journal of Human Sciences, 17(4), 1312-1322. doi:10.14687/jhs.v17i4.6110

Tablo 5. Katılımcıların IPAQ Düzeyleri İle Düzenli Olarak Fiziksel Aktivite yapma Durumları Arasındaki İlişkiye Ait Analizi Sonuçları.

\begin{tabular}{|c|c|c|c|c|c|}
\hline \multicolumn{6}{|c|}{ Düzenli olarak fiziksel aktivite yapiyor musunuz? } \\
\hline IPAQ & & Evet & Hayır & $\mathrm{X}^{2}$ & $\mathrm{p}$ \\
\hline \multirow{3}{*}{ İnaktif } & $\mathrm{n}$ & 0 & 50 & \multirow{8}{*}{$-100,0$} & \multirow{8}{*}{$0,000^{* *}$} \\
\hline & $\%$ & 0,00 & 100,00 & & \\
\hline & $\mathrm{n}$ & 22 & 0 & & \\
\hline \multirow[t]{2}{*}{ Minimal } & $\%$ & 44,00 & 0,00 & & \\
\hline & $\mathrm{n}$ & 28 & 0 & & \\
\hline \multirow[t]{2}{*}{ Çok Aktif } & $\%$ & 56,00 & 0,00 & & \\
\hline & $\mathrm{n}$ & 50 & 50 & & \\
\hline Toplam & $\%$ & 100,00 & 100,00 & & \\
\hline
\end{tabular}

**p<0.01; \#Yüzdeler sütunlara göre verilmiştir.

Tablo 6'dakatılımcıların IPAQ düzeyleri ile aktif olarak sporla uğraşma süreleri arasındaki ilişkiyi belirlemek için ki-kare analizi yapılmıştır. Yapılan ki-kare analizi sonucuna göre IPAQ grupları ile aktif olarak sporla uğraşma süreleri arasında anlamlı bir ilişki olduğu $\left(X^{2}=113,366 ; p<0.01\right)$ belirlendiğinden H12 kabul edilmiştir. Genelde spor yapmayanların tamamının (\%100) inaktif IPAQ grubunda, 31-40 yıl arasında ve 41 yıl ve üzeri spor yapanların tamamının (\%100) çok aktif IPAQ grubunda oldukları, 21-30 yıldır spor yapanların \%40'ının minimal, \%60'ının ise Çok aktif grubunda, 10-20 yil arasında spor yapanların \%48,50'sinin inaktif, \%48,50'sinin minimal ve \%3'ünün çok aktif grubunda oldukları belirlenmiştir.

Tablo 6. Katılımcıların IPAQ Düzeyleri İle Sporla Uğraşma Süreleri Arasındaki İlişkiye Ait Analizi Sonuçları

\begin{tabular}{|c|c|c|c|c|c|c|c|c|}
\hline \multicolumn{9}{|c|}{ Kaç yıl aktif sporla uğraştınız } \\
\hline IPAQ & & $10-20 \mathrm{y} 1 \mathrm{l}$ & $21-30 \mathrm{y1l}$ & $31-40 \mathrm{y} 11$ & 41 y1l veya üzeri & Genelde Spor Yapmam & $\mathbf{X}^{2}$ & $\mathrm{p}$ \\
\hline & $\mathrm{n}$ & 16 & 0 & 0 & 0 & 34 & \multirow{8}{*}{113,366} & \multirow{8}{*}{$0,000^{* *}$} \\
\hline Inaktif & $\%$ & 48,50 & 0,00 & 0,00 & 0,00 & 100,00 & & \\
\hline & $\mathrm{n}$ & 16 & 6 & 0 & 0 & 0 & & \\
\hline Minimal & $\%$ & 48,50 & 40,00 & 0,00 & 0,00 & 0,00 & & \\
\hline & $\mathrm{n}$ & 1 & 9 & 10 & 8 & 0 & & \\
\hline Çok Aktif & $\%$ & 3,00 & 60,00 & 100,00 & 100,00 & 0,00 & & \\
\hline & $\mathrm{n}$ & 33 & 15 & 10 & 8 & 34 & & \\
\hline Toplam & $\%$ & 100,00 & 100,00 & 100,00 & 100,00 & 100,00 & & \\
\hline
\end{tabular}

**p<0.01; \#Yüzdeler sütunlara göre verilmiştir.

\section{Tartışma}

Yapılan bu araştırmada katılımcıların fiziksel aktivite yapma durumları incelendiğinde, katılımciların \%33'ünün 10-20 y1l arası sporla ilgilendikleri, \%15'inin 21-30 yıldır sporla ilgilendikleri, $\% 10$ 'unun 31-40 y1, \%8'inin ise 41 ylldan fazla sporla ilgilendikleri (futbolla ilgilendikleri) belirlenirken \%34'ünün genelde spor yapmadıkları belirlenmiştir. Katılımcıların \%50'sinin düzenli spor yaparken $\% 50$ 'sinin ise düzenli spor yapmadıkları (sedanter) tespit edilmiştir. Spor yapanların $\% 58$ 'inin haftada 3-4 gün, \%42'sinin 5 gün veya üzerinde spor yaptıkları bulunmuş olup, katılımcıların \%13'ünün genel olarak kendi sağlık durumlarını çok kötü olarak değerlendirirken, \%38’inin kötü, \%12'sinin normal, \%10'unun iyi ve \%27'sinin ise çok iyi olarak değerlendirdikleri görüldü. Katıllımcıların Uluslararası Fiziksel Aktivite Değerlendirme Anketi Kısa Formuna verdikleri cevaplanın değerlendirilmesi sonucunda; \%50'sinin inaktif (en alt fiziksel aktivite seviye) gruba, \%22'sinin minimal gruba ve $\% 28$ 'sinin çok aktif (en az günde bir saat veya daha fazla olan orta şiddetli bir aktivite yapan) gruba dahil oldukları tespit edildi. 
Gönen, A. İ., \& Türkmenoğlu, İ. (2020). 50 yaş üstü futbol oynamış bireylerle aynı yaş grubu sedanter bireylerin yaşam kaliteleri bağlamında karşılaştırılmaları. Journal of Human Sciences, 17(4), 1312-1322. doi:10.14687/jhs.v17i4.6110

Katılımcıların yaşam kalite düzeylerinin medeni duruma göre farklılaşıp farklılaşmadığını belirlemek adına bağımsız t testi yapılmış ve anlamlı bir farklılık görülmüştür. Evli olanların yaşam kalite düzeyleri bekar olanlara göre yüksek çıkmıştır. Yine yaşam kalite düzeylerinin alt boyutlarının medeni duruma göre farklılaştı̆g tespit edilmiştir. Fiziksel kalite, psikolojik kalite, bağımsızlık kalite, sosyal kalite ve çevresel kalite boyutlarının medeni duruma göre farklılaştığı ve evli olanların bu kalite düzeyleri bekâr olanlara göre daha yüksek çıkmıştır.

Katılımcıların yaşam kalite düzeylerinin düzenli spor yapma durumlarına göre farklılaşıp farklılaşmadığını belirlemek adına bağımsız t testi yapılmış ve anlamlı bir farklılık görülmüştür. Düzenli spor yapanların yaşam kalite düzeyleri düzenli spor yapmayanlara göre yüksek çıkmışır. Yine yaşam kalite düzeylerinin alt boyutlarının düzenli spor yapma durumlanına göre farklılaştığ1 tespit edilmiştir. Fiziksel kalite, psikolojik kalite, bağımsızlık kalite, sosyal kalite ve çevresel kalite boyutlarının düzenli spor yapma durumlarına göre farklılaştığ1 ve düzenli spor yapanların yaşam kalite düzeyleri boyutları düzenli spor yapmayanlara göre yüksek çıktığ1 görülmüştür.

Çalışmamızda katılımcılarımızın yaşam kalitesi düzeylerini, BKİ göre ilişkilendirdiğimizde ise Vural, Eler ve Güzel'in (2010) yapmış olduğu çalışmada olduğu gibi yaş gruplarının yaşam kalitesi anlamında anlamlı bir ilişki bulunmamıştır. Eğitim durumlarının yaşam kalitesine anlamlı bir farklılık gösterememesi araşturlması gereken dikkat çekici bir olgudur.

Katılımcıların yaşam kalitesi düzeylerinin IPAQ gruplarına göre farklılaşıp farklılaşmadığını belirlemek adına anova testi yapılmış ve anlamlı bir farklılık görülmüştür. IPAQ grubu çok aktif olanların yaşam kalitesi düzeyleri IPAQ grubu inaktif veminimal olanlara göre daha yüksek olduğu belirlenmiştir.Yine yaşam kalite düzeylerinin alt boyutlarının IPAQ gruplarına göre farklılaştığı tespit edilmiştir. Fiziksel kalite, psikolojik kalite, bağımsızlık kalite, sosyal kalite ve çevresel kalite boyutlanının IPAQ gruplarına göre farklılaştı̆ı ve IPAQ grubu çok aktif olanların yaşam kalitesi düzeyleri IPAQ grubu inaktifve minimal olanlara göre daha yüksek olduğu tespit edilmiştir.

Katılımcıların IPAQ düzeyleri ile düzenli olarak fiziksel aktivite yapma durumları arasındaki ilişkiyi belirlemek için ki-kare analizi yapılmıştır. Yapılan ki-kare analizi sonucuna göre IPAQ grupları ile düzenli olarak fiziksel aktivite yapma arasında anlamlı bir ilişki olduğu belirlenmiştir. Fiziksel aktivite yapanların \%44'ünün minimal IPAQ grubunda, \%56'sının ise çok aktif IPAQ grubunda oldukları düzenli olarak fiziksel aktivite yapmayanların ise tamamının inaktif IPAQ grubunda oldukları görülmüştür.

Katılımcıların IPAQ düzeyleri ile aktif olarak sporla uğraşma süreleri arasındaki ilişkiyi belirlemek için ki-kare analizi yapılmıştır. Yapılan ki-kare analizi sonucuna göre IPAQ grupları ile aktif olarak sporla uğraşma süreleri arasında anlamlı bir ilişki olduğu belirlenmiştir. Genelde spor yapmayanların tamamının inaktif IPAQ grubunda, 31-40 yll arasında ve 41 yll ve üzeri spor yapanların tamamının çok aktif IPAQ grubunda oldukları, 21-30 yıldır spor yapanların \%40'inın minimal, \%60'ının ise Çok aktif grubunda, 10-20 yll arasında spor yapanların \% 48,50'sinin inaktif, \%48,50'sinin minimal ve \%3’ünün çok aktif grubunda oldukları tespit edilmiştir.

Sonuç olarak, bu çalışmada; evli olan katılımcıların bekar olanlara göre, düzenli bir şekilde spor yapanların yapamayanlara göre, haftada 5 gün ve üzerinde spor yapanların daha az sıklıkta spor yapanlara göre, 41 yıl ve üzerinde aktif spor yaşamı olanların daha az yıl spor yapanlara göre, genel sağlık durumu çok iyi olanların olmayanlara veyoğun fiziksel aktivite yapan kişilerin yapmayanlara göre yaşam kalitesinin yüksek olduğu görülmüştür. Bu da 50 yaş üstü kişilerin 50 yaş öncesinde ve sonrasında futbol oynamış bireylerle sedanter bireylerin yaşam kalitesi açısından farklılaştı̆̆1 ve bir şekilde fiziksel aktivite yapmış kişilerin diğer bireylere göre yaşam kalitesinin daha yüksek olduğu sonucuna varılmıştır. Sedanter bireylerin toplu taşıma araçlarında oturmak yerine ayakta durmaları, çalışanların iş yerine yürüyerek gidip gelmeleri, masa başında çalışan kişilerin her 30 dakika da bir kalkıp küçük fiziksel aktiviteler yapmaları teşvik edilmelidir.Ayrıca bireyleryaşamlarını daha kaliteli hale getirebilmek için günlük yaşamda çok fazla zaman ayırdıkları bilgisayar ve internette dolaşmak yerine daha çok fiziksel hobilerle vakit geçirmeli, asansör kullanmak yerine merdivenleri tercih etmelidirler. 
Gönen, A. İ., \& Türkmenoğlu, İ. (2020). 50 yaş üstü futbol oynamış bireylerle aynı yaş grubu sedanter bireylerin yaşam kaliteleri bağlamında karşılaştırılmaları. Journal of Human Sciences, 17(4), 1312-1322. doi:10.14687/jhs.v17i4.6110

\section{KAYNAKLAR}

Akcan , F. (2013). Çesitti Branslardaki Erkek Sporculara Uygulanan İki Farkli Kuvvet Antrenman Programmm Fizilesel ve Fizyolojik Özellikleri Üzerine Etkisi. Gaziantep : Gaziantep Üniversitesi, Yayınlanmış Yüksek Lisans Tezi.

Brown, D. W., Balluz, L. S., Heath, G. W., Moriarty, D. G., Ford, E. S., \& Giles, W. H. (2003). Associations between recommended levels of physicalactivityandhealth- relatedquality of life. Preventive Medicine(37), 520-528.

Craig, C. L., Marshall, A.L., Sjostrom, M., Bauman, A. E., Booth, M. L. (2003). International physical activity questionnaire: 12 -country reliability and validity. Medicine and Science in Sports and Exercise(35), 13811395.

Çolakoğlu, F. F. (2003). 8 Haftalık Koş-Yürü Egzersizinin Sedanter Orta Yaşlı ObezBayanlarda Fizyolojik,Motorik ve Somatotip Değerleri Üzerine Etkisi. Gazi Eğitim Fakültesi Dergisi, 23(3), 275-290.

Fişne, M. (2009). Fiə̨ikesel Aktivitelere Katılım Düzeyinin Üniversite Öğrencilerinin Akademik Başarlar İetişim Becerileri Ve Yaşam Tatminleri Ürerine Etkilerinin Incelenmesi. Kayseri: Erciyes Üniversitesi, Yayınlanmamış Yüksek Lisans Tezi.

Fraenkel, J. R., Wallen, N., \& Hyun, H. (2012). How To Design And Evaluate Research In Education (8. b.). New York: McGraw-Hill.

Gumus, H., Isik, O. (2018). The relationship of physical activity level, leisure motivation and quality of life in candidate teachers. International Journal of Progressive Education, 14(5): 22-32.

Gümüş, H. Erbaş Ü. (2020). The relationship between leisure activity types selected by older adults and their income. Studia Periegetica. 29 (1) 1-11.

Işık, Ö., Gümüş, H., Okudan, B., \& Yilmaz, M. (2014). Evaluation of the effects of the quality of life levels of university students upon their depression levels. International Journal of Science Culture and Sport (IntJSCS), 2(5), 836- 843.

İmamoğlu, A. F., Koçak, M., \& Sunay, H. (1996). Türkiye ve Bazı Avrupa Ülkelerinde (Almanya, İngiltere ve İskoçya) Futbol Antrenör Yetiştirme Programlarının Karşılaştırmalı Olarak İncelenmesi. Gazi Üniversitesi Beden Eğitimi ve Spor Bilimleri Dergisi, 1(4), 75-84.

Karaca, A., Turnagöl, H.H. (2007). IPAQ anketinin geçerlilik ve güvenirlilik çalışması. Hacettepe Üniversitesi Spor Bilimleri Dergisi, 18(2), 68-84.

Koçak, Y., Tukul, U., Tolan, B., Gümüş, H., \& Tolukan, E. (2017). Spor ve Sağlıklı Yaşam Merkezlerinde Hizmet Kalitesine Yönelik Müşteri Beklentilerinin ve Algılarının Analizi (Afyonkarahisar İli Örneği). International Journal of Recreation and Sports Science, 1(1), 38-46.

Köklü, Y., Özkan, A., \& Ersöz, G. (2009). Futbolda Dayanıklılık Performansının Değerlendirilmesi ve Gerçekleştirilmesi. Celal Bayar Üniversitesi Beden Eğitimi ve Spor Bilimleri Dergisi, 4(3), 142 150.

Özdoğan, H. (2008). Beden Eğitimi Öğretmenlerinde Mesleki Tükenmişlik. Sivas: Cumhuriyet Üniversitesi, Yayınlanmış Yüksek Lisans Tezi.

Vural, Ö., Eler, S., \& Atalay Güzel, N. (2010). Masa başı çalışanlarda fiziksel aktivite düzeyi ve yaşam kalitesi ilişkisi. Spormetre Beden Ë̆itimi ve Spor Bilimleri Dergisi, 8(2), 69-75.

Yilmaz, M., Sertbaş, K., \& Gumus, H. (2019). Gönüllülerin Faaliyetlere Katilim Nedenleri ve Motivasyonel Faktörlerin Analizi: Gençlik Merkezleri Örneği. Beden Eğitimi ve Spor Bilimleri Dergisi, 21(3), 117-127.

\section{Extended English Summary}

Sport, while it is a technical and physical occupation based on winning for those who do it, is an aesthetical process based on competition for spectators. For society, it is, at times a broadcast that conveys its characteristics and controversies and at times it is a purpose that directs the society. In general, it is an essential institution for the society (Özdoğan, 2008).

Sport, which is an indispensable need in today's modern world, is one of the most important areas invested in by the most developed countries. Sport is a requirement that meets the 
Gönen, A. İ., \& Türkmenoğlu, İ. (2020). 50 yaş üstü futbol oynamış bireylerle aynı yaş grubu sedanter bireylerin yaşam kaliteleri bağlamında karşılaştırılmaları. Journal of Human Sciences, 17(4), 1312-1322. doi:10.14687/jhs.v17i4.6110

psychological, socio-economical and psychomotor needs of people (Akcan, 2013). At the present time, sport has maintained its cultural, economic and social progress and become a great factor in establishing a communication between societies. Especially football has become a sport activity with the highest audience participation and potential in all societies. (İmamoğlu, Koçak and Sunay, 1996) It easily differs from other sports activities with its large competition field, high number of players and its orientation towards winning and competition (Köklü, Özkan, Alemdaroğlu and Ersöz, 2009).

It is known that individuals who have sedentary lifestyles with little movement have negative bodily integrity and are unhappier than athletes who exercise regularly. Many studies have been conducted on sedentary individuals and those who do sports on a regular basis. The increasing use of technological tools in almost every activity done by an individual during the day, the convenience provided in transportation and widespread use of smart home appliances have decreased energy consumption by limiting physical activities. As the individual ages that results in the decrease of movement, the need for energy becomes less (Çolakoğlu, 2003). In order to have healthy individuals in society, the benefits of physical activities should be known and suitable activities should be done for individuals. Physical activities have a huge impact on long and high quality of life. Physical activities done in childhood will not suffice and therefore it is of great importance to continue with physical activities in adulthood and old age (Yüksel 2001, cited by Fişne, 2009). As a result of study conducted by Vural, Eller and Atalay Güzel (2010), they tried to explain the relation between the levels of physical activity and life quality of white-collar workers in the municipality of Ankara. However, no relation between the levels of physical activity and quality of life scores was found because these people had low rates of physical activity. Brown and colleagues (2003) used the 2001 Behavioral Risk Factor Surveillance survey in their study that analyses the relation between physical activity and life quality of 175.850 adult participants. In order to determine probability ratio, multivariate regression analysis with $\% 95$ confidence range was applied on variants such as ethnicity, age, gender, educational background, body mass index and smoking status. According to the findings obtained as a result of the analysis, a significant difference was found between ethnicity, age and gender groups who did physical and mental activities for 15 days and those who were at the level of physical activity. In this study, it is aimed to analyze the life quality of individuals over 50 years of age who have played football and their peers who have sedentary life style.

The study is in the quantitative model which is one of the quantitative models that enables researchers gather the opinions of participants on a particular subject through a survey and to compare these opinions among groups (Fraenkel, Wallen and Hyunn,2012). The population of the study consists of individuals over 50 years old living in the municipality of Afyon and playing football and the sample consists of 100 volunteers (50 of whom do regular physical activities and the other 50 who do not do any physical activities) who agreed to fill in a questionnaire. One of the data collecting tools, the questionnaire was presented to the field by the researcher in March 2019. When examined the number of individuals who filled in the questionnaire, the number of items in the scale was approximately four times higher.

In the first part of the questionnaire used in the study, besides six questions for identifying demographic features of the participants, other questions are included in regard to how long they have been actively involved in sports for, whether they actively do sports and how they assess their general health. In the second part of the questionnaire, "International Physical Activity Assessment Questionnaire Short Form" was used. In the third part of the questionnaire, in order to determine the activity levels of the participants, the five-point Likert scale with twenty-three questions was presented. The data obtained was analyzed in SPSS 25 program. Frequency and percentage analysis was carried out to understand the distribution of the participants. To study the distribution of data collected from the participants, one of the normal distribution analyzes, Kolmogrov-Smirnova was conducted. After determining that the distribution came from normality, one-way Anova analysis was done on more than two groups to compare independent sample test of groups of two. Schaffe analysis, a post-hoc analysis, was conducted to identify from which group the difference came. Chisquare test was done for finding the relation between categorical variants. Cronbach's Alpha analysis 

kaliteleri bağlamında karşılaştırılmaları. Journal of Human Sciences, 17(4), 1312-1322. doi:10.14687/jhs.v17i4.6110

was done for determining the levels of confidence pertaining to the quality of life scale used in the study.

As a results of this study, higher level of life-quality was observed in participants who are married, exercise on a regular basis and do sports five days a week or more in comparison to participants who are single, do not exercise regularly and do sports less frequently. Also, participants who have actively engaged in sports activities for over 41 years have higher level of life-quality than those who have engaged in sports activities in much less than 41 years. In addition, participants who are in good health have higher level of life-quality than those who are not in good health and those who do intense exercise have higher level of life-quality than those who do not do intense exercise. It was concluded that people who have played football before or after 50 years of age and people who lead sedentary lives differ in terms of quality of life and individuals who have effectively taken part in physical activities have higher quality of life than those than others. Sedentary individuals should be encouraged to stand on public transport and workers to walk to their workplace, whitecollar workers to do little exercise every 30 minutes instead of sitting on public transport, driving to workplace. Moreover, individuals should focus on spending more time on hobbies rather than spending time on their tablets and computers and take the stairs rather than taking the elevator. 